\title{
NotA DE LA REDACCIÓN
}

Iniciamos en este número tres nuevas secciones de la Revista que merecen una breve presentación.

En primer lugar, la Sección "Análisis de la doctrina judicial y constitucional”, con un brillante comentario de jurisprudencia constitucional del Prof. Cabeza Pereiro, en torno a la discriminación por razón de sexo, en la que es un consagrado experto. Se abre así un espacio para el estudio y reflexión sobre los pronunciamientos de los tribunales a todos los niveles; algo que resulta imprescindible en un Estado de Derecho donde los jueces tienen la última palabra a la hora de aplicar la ley, pero, a su vez, palabra de la que, lógicamente -a partir del derecho a la libertad de expresión que nuestra Carta Magna reconoce en su art. 18-, se podrá suscribir o discrepar, siempre desde el respeto como base de todo diálogo.

En segundo lugar, la Sección "Colaboración novel”. Como ya comentara el Director en el Editorial de TPDM 1/2020, la Revista quiere ofrecer un espacio reservado a alumnos/as tanto de Grado, como de Máster y Doctorado, para que puedan publicar sus primeros trabajos de investigación. Pensamos que esto constituye -sin duda- un notable aliciente para ellos, pues ven que lo que han trabajado con empeño y dedicación encuentra una vía de difusión. Nos parece no solo que será una fuente de descubrimiento de jóvenes promesas, sino que, al mismo tiempo, les ayudará a enriquecer sus curricula vitae, pues de este modo dispondrán de un artículo publicado en una Revista científica. La inauguramos con un brillante trabajo realizado por tres alumnas del Grado en Derecho de la Universidad de Sevilla sobre el convenio colectivo como fuente del Derecho y su cuestionamiento como instrumento suficientemente garantista de derechos laborales en los tiempos presentes.

El último estreno lo constituye la Sección "From my workspace", dedicada a todos los profesionales que, vinculados directa o indirectamente con las áreas de interés de la Revista, quieran colaborar aportando una visión más práctica que complemente la académica. En este caso, el abogado Cordero Márquez nos ayuda a reflexionar sobre el foro territorialmente competente para resolver las demandas por despido de los teletrabajadores.

Consejo de Redacción

Copyright: (C) Editorial Universidad de Sevilla. Este es un artículo de acceso abierto distribuido bajo los términos de la licencia de uso y distribución Creative Commons Reconocimiento-NoComercialSinObraDerivada 4.0 (CC BY-NC-ND 4.0)

e-ISSN: 2660-4884

Trabajo, Persona, Derecho, Mercado 4 (2021) 25-25

https://dx.doi.org/10.12795/TPDM.2021.i4.02 